American Journal of Environmental Sciences 7 (4): 338-347, 2011

ISSN 1553-345X

(C) 2011 Science Publications

\title{
Main Aspects of Tunnel Muck Recycling
}

\author{
Rossana Bellopede, Fabrizio Brusco, \\ Pierpaolo Oreste and Maurizio Pepino \\ Department of Land, Environment and Geotechnology Engineering, \\ Politecnico di Torino Corso Duca Degli Abruzzi 24, Torino, Italy
}

\begin{abstract}
Problem statement: Italy is one of the first countries in the world as far as the number of tunnels is concerned. Many new tunnels are currently under construction or have been planned (300 $\mathrm{km}$ of railway tunnels and $150 \mathrm{~km}$ of road tunnels, some more than $500 \mathrm{~m}$ long, but also metropolitan tunnels). Tunnels are usually excavated in mountain areas of great value: the longest ones in Italy are in fact located in the Alps or in the Apennine mountain range. Approach: If the re-use of excavated material is not taken into account each time a tunnel is excavated, new quarries are required to obtain aggregates for cement, asphalt and concrete and new landfills are created, to allocate the tunnel muck. If the planned tunnel is large (in size and length), numerous quarries and landfills can be expected in the vicinity of the tunnel, with a consequent considerable amount of environmental damage. Results and Conclusion: For these reasons and not only for the obvious economic reasons, it is necessary to develop all the technologies that make the re-use of muck possible as an aggregate for cement and asphalt and as material for road and railways embankments.
\end{abstract}

Key words: Excavation material, tunnel excavation, explosives reduction, fragments sieving, natural material, under construction, excavated material, excavated rock, intermediate storage, jaw crushers, swiss francs, rock fragmentation

\section{INTRODUCTION}

Over the past forty years, the construction of public works has been increasing considerably all over the world and particularly in Europe in order to improve the mobility of people and goods. This increase is mainly due to the expansion of economic integration and because of the opening of new frontiers. In the 80 's, the European Union defined different trans-European transport networks (TEN-T), which involved road, rail, maritime and air traffic and satellite navigation and positioning. In 1994, the European Council approved a list of 14 specific TEN-T projects and in 2005 the European Commission drew up a new list of 30 priority projects.

Of these projects, two axes affect the Italian territory: priority axis 1 : the Berlin-Verona-MilanBologna-Naples-Messina-Palermo railway axis, for which the $57 \mathrm{~km}$ long Brenner base tunnel is going to be excavated (this will be the longest railway tunnel of the world) and priority axis 6: the Lyons-Trieste-LjubljanaBudapest-the Ukraine border railway axis for which a base tunnel will be excavated between Turin and Lyons with an expected length of $52 \mathrm{~km}$.
Underground soil exploitation will be used more and more in the coming years throughout Europe. Because of the presence of mountain ranges, such as the Alps in the North and the Apennines, which run all along its length, Italy has always been one of the countries with the highest concentrations of tunnels: it is sufficient to consider the number of already existing tunnels that are longer than $500 \mathrm{~m}$, which add up to a total of about $850 \mathrm{~km}$ and an additional $150 \mathrm{~km}$ of tunnels (updated in November 2009) are under construction. There are $750 \mathrm{~km}$ of existing railway tunnels lines that are longer or equal to $50 \mathrm{~m}, 130 \mathrm{~km}$ under construction and $170 \mathrm{~km}$ at the draft stage. It is important to recall that there are more than $150 \mathrm{~km}$ of underground metropolitan tunnels in Italy which will be increased with the addition of new sections to enlarge the already existing lines or the construction of new infrastructures (Naples, Rome, Turin, Brescia, Catania, Milan).

These data show that, in the coming years, there will be a notable production of excavated material from tunnels: 13.3 million $\mathrm{m}^{3}, 14$ million $\mathrm{m}^{3}$ and 17 million $\mathrm{m}^{3}$ of excavated rock from the construction of the Gotthard tunnel, the Turin-Lyons tunnel and the Brenner

Corresponding Author: Pierpaolo Oreste, Department of Land, Environment and Geotechnology Engineering,

Politecnico di Torino, Corso Duca degli Abruzzi, 24-10129 Torino, Italy 
base tunnel, respectively. Each tunnel will be excavated at low altitudes in order to reduce the slope and length of the entrances and this will also lead to increase train speeds and energy savings.

The availability of a large quantity of excavated material, which can be recycled as aggregates for concrete for the construction of retaining walls and for the lining of tunnels, can be expected.

A huge amount of concrete is required for the construction of a tunnel and this quantity depends on the construction method, the size and the geo-mechanical properties of the rock. For example, an excavation area of $90 \mathrm{~m}^{2}$, in medium-poor soils using conventional systems, which involves the use of temporary and final supports, requires the following materials: shotcrete (thickness $25 \mathrm{~cm}$ ): $6 \mathrm{~m}^{3} \mathrm{~m}^{-1}$, in situ concrete $(90 \mathrm{~cm}$ thick on average): $40 \mathrm{~m}^{3} \mathrm{~m}^{-1}$, volumetric percentage of the concrete to the total excavated volume: $51 \%$. The average percentage of costs for the tunnel is about $15 \%$ for shotcrete and $18 \%$ for in situ concrete. The production of $1 \mathrm{~m}^{3}$ of concrete for tunnel linings takes about $1500 \mathrm{~kg}$ of aggregates (sand and gravel sized from 0-32 mm) and some hundreds of kilograms of cement, depending on the strength that needs to be obtained. The production of shotcrete requires about $1000 \mathrm{~kg} \mathrm{~m}^{-3}$ of gravel and sand. The construction of one kilometre of tunnel takes about 66 tons of aggregates.

From these considerations, it is obvious that the construction of several long tunnels will produce large amounts of excavated material and, at the same time, will produce a high demand for aggregates for the required linings. If the excavated material is considered as a waste rather than a possible resource, the double problem arises of having to resort to non-renewable resources (extracted from quarries) and of having to find areas for the disposal of the unused muck, with the consequent environmental impact.

The aggregates required for the construction of tunnels should be retrieved from quarries in the vicinity of the site. In recent years, mining operations, like most industrial activities, have been cited as being responsible for many adverse environmental effects, which are considered to be more and more of primary importance. This is due to several reasons, for example the growing awareness of citizens towards environmental issues, which results in a general increase in a "demand for quality: of the environment. In a very anthropised area full of natural beauties, which as in the case in most Italian regions, it is unavoidable that environmental protection requirements clash with the demand for raw materials (Blengini and Garbarino, 2010).

In this context, especially in the "sustainable mobility" sector, the RE-MUCK project plays an important role. Funded by the Regione Piemonte, it develops innovative methods to reduce problems related to the disposal of tunnel excavation material and to optimize the management of the reuse process by making it economically feasible.

\section{MATERIALS AND METHODS}

The choice of the final use of tunnel muck is not the same for all tunnels and it depends on many factors (environmental, technical, economic, geological, etc.). Among these, mention can be made of the following:

- The quality of the extracted rock, for the purposes of reuse as subsoil material, as an aggregate for concrete or as filling material

- The option to use spaces close to each other as the final destination, in an economic way

- The possibility of installing facilities in sites in the vicinity to treat the mucks so that they can be reused

- The presence of hazardous substances above the legal limits

Among the lithological characteristics, the main properties that can be found at a decimeter scale in the material from the excavation of tunnels are the mineral composition, the texture and the alteration of the components.

In general, these data are already available after the geological studies have been carried out, but petrographic analysis are also conducted during the construction of tunnels in order to have detailed information on the changes in the characteristics of the rock along the planned path of the tunnel.

The rock properties are also determined by carrying out some tests on some representative specimens of the muck. The tests are carried out to assess the apparent density, the porosity, the water absorption coefficient, the permeability, the mechanical strength (static and dynamic), the elastic modulus, the Poisson ratio, the hardness, the abrasion resistance. These tests are related to the excavated rock, not only in order to suggest the best subsequent use, but also to obtain feedback on the project. In order to be used as aggregates for concrete, the muck must not have a significant amount of soft minerals (clay, gypsum, talc), very hard minerals (granat), lamellar or fibrous minerals (micas, graphite, asbestos). Among the chemical properties that adversely affect the re-use of muck, mention can be made of the high solubility (chlorides, sulphates, gypsum), the alterability (anhydrite, pyrite) and the reactivity of alkali. 
Am. J. Environ. Sci., 7 (4): 338-347, 2011

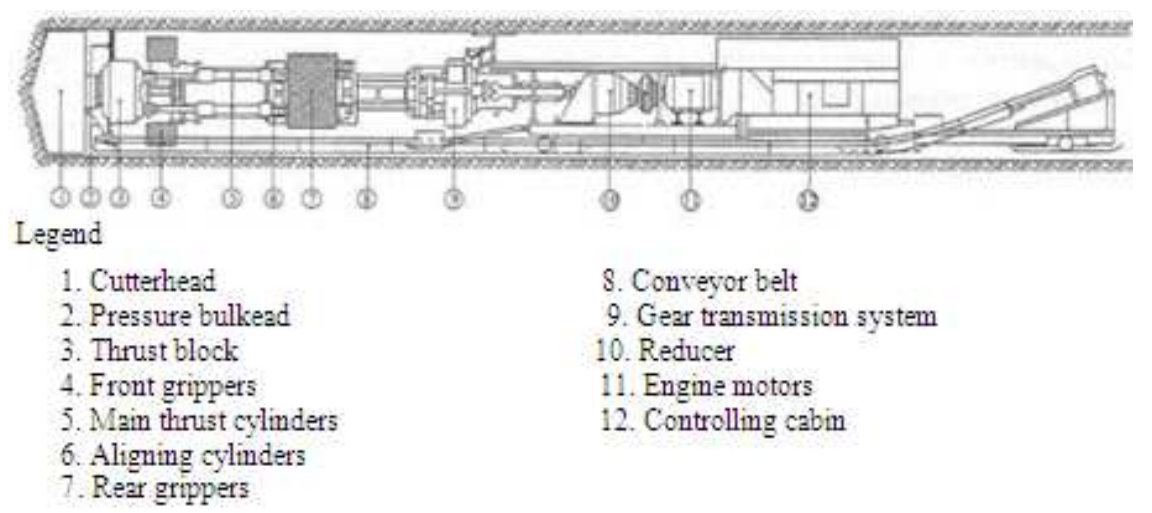

Fig. 1: Tunnel Boring Machine (TBM) for tunnel excavation in rock

The geometric characteristics of the excavated material is affected by the excavation method that is used; muck obtained from TBMs (Tunnel Boring Machines) (Fig. 1) is more difficult to reuse for concrete than muck obtained from drill and blast excavations, as the typical form of the granules that are produced is lamellar and these grains tend to form horizontal planes during the concreting phase. Furthermore, they trap some of the water in the mixture, causing a consequent degradation of the final structure. The surface roughness and the presence of sharp edges improve the bond between the aggregates and concrete, but reduce the workability and require a greater quantity of water and cement and therefore increased costs.

A key aspect that must be considered in the evaluation of the possible use of muck from the excavation of tunnels is that aggregates need high strength against alkali. This is because of the phenomenon that is known as the "alkali-silica reaction" (or ASR). This phenomenon represents a form of chemical degradation of concrete that is triggered by the presence of aggregates which are characterized by a particular mineralogical composition.

The alkali-aggregate reaction is generally associated with the presence of alkali (sodium and potassium) in the cement and amorphous or poorly crystalline silica in some aggregates.

Cement contains small quantities of alkali $\left(\mathrm{Na}_{2} \mathrm{O}\right.$ and $\mathrm{K}_{2} \mathrm{O}$ ) (due to the clay component) which after hydration form a hydroxide solution Eq. 1:

$\mathrm{Na}_{2} \mathrm{O}+\mathrm{H}_{2} \mathrm{O} \rightarrow 2 \mathrm{NaOH}$

$\mathrm{K}_{2} \mathrm{O}+\mathrm{H}_{2} \mathrm{O} \rightarrow 2 \mathrm{KOH}$

Reactive aggregates react with hydroxyl ions $(\mathrm{OH}-)$ associated with alkali and give rise to expanding products.

As a result of the reaction, an alkaline silicate gel appears on the surface of the granules and this gel, if dampened with water, swells and develops a pressure between the grains and the cement paste.

This process is slow and the expansion occurs during concrete hardening; the increase in intergranular pressure can lead to localized swelling and cracking of the concrete, thereby ruining it. A white liquid gel (sodium silicate) escapes from the irregularly shaped cracks. Cracking is usually followed by the detachment of a small circular portion of the concrete surface area (popout), because of the swelling of the reactive aggregates.

Although the exact alkali-aggregate reaction mechanism is not fully understood, some basic parameters that contribute to the progression of the destructive phenomenon have been identified.

The alkali-aggregate reaction occurs as rapidly and intensely as the increase in:

- The sodium and potassium content in the aqueous phase which fills the capillary pores of the cement paste: A content in excess of $3 \mathrm{~kg} \mathrm{~m}^{-3}$ is considered dangerous

- The relative humidity of the environment

- The quantity of amorphous and cryptocrystalline siliceous aggregates

- If any of these three conditions is missing, the phenomenon will not occur and there will be no apparent damage (Collepardi et al., 2002)

\section{RESULTS}

The importance of the muck granulometric size when TBMs are used: Large and very long tunnels are now almost always excavated using full face excavation machines (TBMs).

The excavation of tunnels in rock by means of TBMs offers several advantages over traditional methods, when the geological conditions allow their use and when the choice of the machine has been made correctly. 
The type of machine that should be used depends on various factors, the most important of which are:

- The geology along the tunnel and the geological uncertainties

- The tunnel length (the assembly time of the machine makes TBMs economic when the tunnel length exceed $5 \mathrm{~km}$ )

- The abrasiveness of the rock types (high abrasiveness means a high consumption of tools and consequently long machine stops caused by frequent tool replacements)

- The hydrogeology

- The diameter of the tunnel

- The kind of supports required

The advantages compared to traditional methods are:

- Safe conditions for the workers (full face machines allow tunnel stabilization ahead of the excavation face and around the tunnel)

- Mechanization of the excavation (the excavation is continuous and the muck is removed from the face with conveyor belts, without hindering or stopping the drilling operations)

- Increased worker comfort (the removal of fumes and gases produced by vehicles)

- Economy (in spite of a high initial investment, TBMs offer more speed)

Rock TBMs have a rotating head, where the milling tools are placed and these tools are exclusively made up of cutting disks that rotate around their axis. The evacuation apparatus of any type of TBM consists of two kinds of machinery placed in different areas:

- Buckets arranged on the periphery of the head in order to remove the debris from the excavation face

- A wing scraper conveyor which receives the rubble from the buckets and reverses it onto the evacuation transport system

The machine back-up consists of a structure that is able to receive the muck and of devices that handle the debris (generally conveyor belts) and supply the working area with the necessary materials (reinforcing elements, spare parts) but also to house equipment that allows the operations relative to the insertion of supports (for example, the projection of the sprayed concrete).

The rock fragmentation process, the tool-rock interaction and the formation of rock fragments, usually in the form of flakes, determined by the use of disks on the head of TBMs, are still not completely understood.

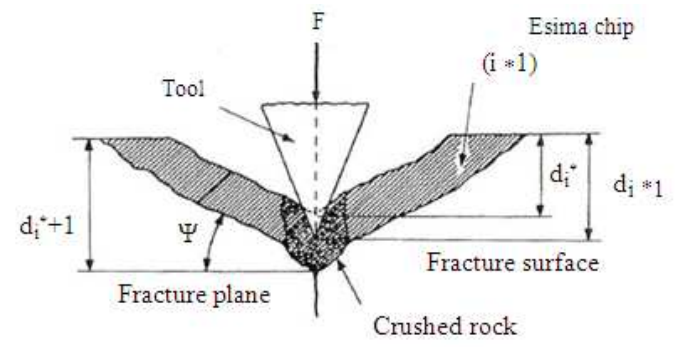

Fig. 2: Fracture formation because of the tool-rock interaction (Paul and Sikarski, 1965)

It has been found that the formation of rock flakes, also known as "chips", is a dynamic phenomenon; the rock involved in the process changes from a millimeter scale, equal to the size of the edge of the disk, to a centimeter scale, when the rock involved is equal to the arc of the circle made by the tool that comes in contact with the rock (Fig. 2) (Paul and Sikarski, 1965).

The muck obtained from TBMs with disk tools has a smaller size than that obtained by means of explosives (Fig. 3) (Girmscheid, 2008) and it is characterized by a typical elongated and flattened shape. The produced material can be divided into four main groups:

- $\quad$ Rock dust generated in the contact zone between the tools (disks) and the rock

- $\quad$ Splinters and rock fragments caused by the cutting and detachment of small rock components

- Flakes, or chips, caused by the detachment of rock fragments between two adjacent tools

- Blocks generated by the detachment of large pieces of rock because of the presence of separation surfaces in the rock (natural joints)

The graph in Fig. 3 (Girmscheid, 2008) shows that the muck produced by TBM excavation can produce a greater amount of fines than conventional excavation with explosives. It should be considered that the volume of disgregated rock, with respect to the volume of rock in place, is increased by a factor of 1.7 when the excavation is carried out using a TBM, against the value of 1.5 when the excavation has been conducted with explosives. Therefore, for the same volume of excavated rock and for the same excavation face area, landfilling is more expensive when TBMs are utilised.

The size of the excavated material depends on the penetration of the hard rock at each revolution of the head. The variables that influence the penetration can be divided into three groups (Cardu et al., 2009): the characteristics of the intact rock, the characteristics of the rock mass (natural discontinuities and intact rock) and the characteristics of the excavation machine (disk size, distance between the tools, force applied at the head). 
Am. J. Environ. Sci., 7 (4): 338-347, 2011

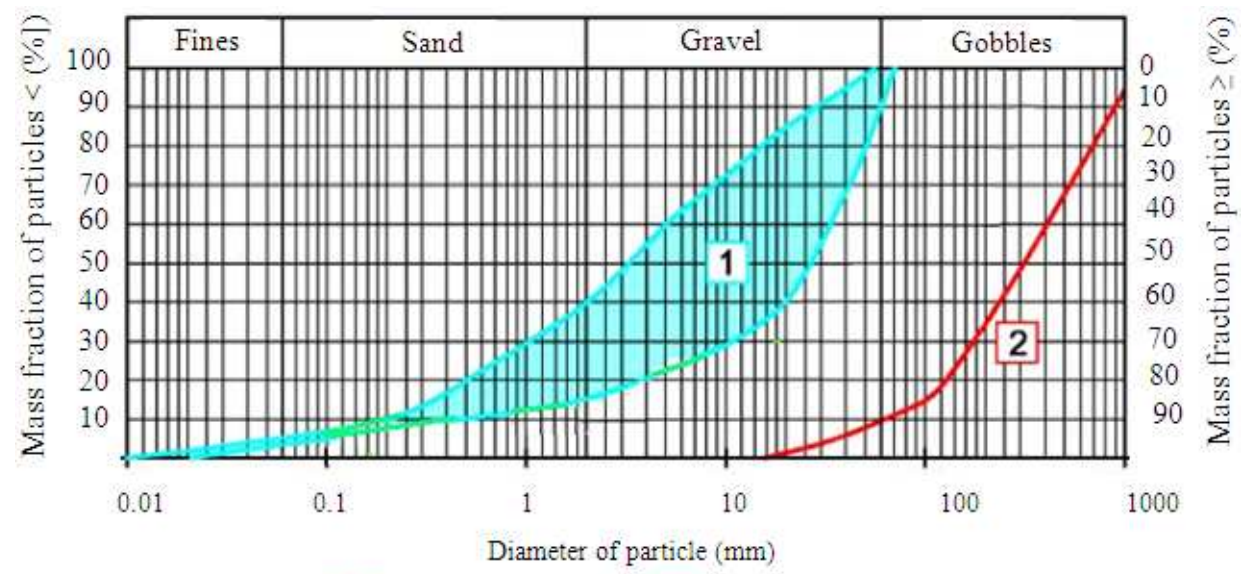

1 Conventional discs 2 Blasted rock

Fig. 3: Grain size distributions for different excavation techniques: TBM excavation and drill and blast excavation (Girmscheid, 2008)

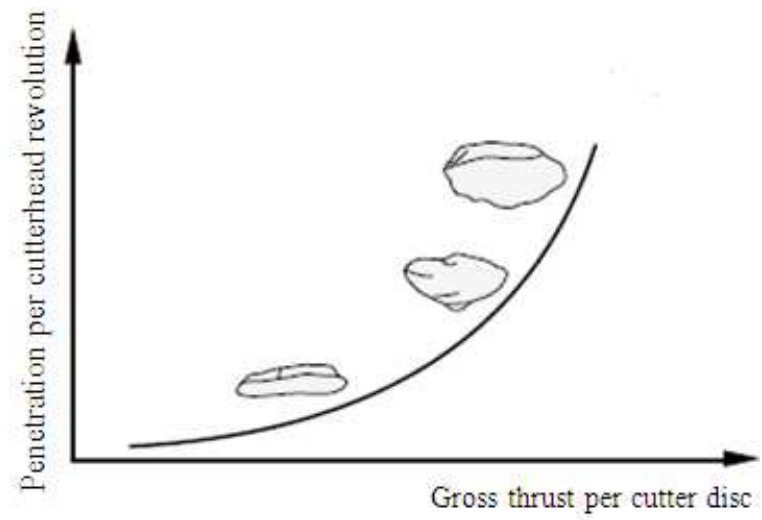

Fig. 4: Penetration and flake shapes and dimensions in function of the tool thrust (Bruland 1999)

A thrust test, conducted with a TBM in Singapore granite (Gong et al., 2007) has shown that a greater depth of cut involves an increased size of the muck. The material appears to have a more uniform size distribution for greater thrusts. In addition, the size of the 25 largest fragments was measured during each thrust test and it was found that the maximum size of the fragments increased with an increase in the thrust.

The spacing between the tools should be large enough to have a useful interaction between the adjacent tools, so that it is possible for the flake formation process to start. Many authors (Bruland, 1999; Gertsh et al., 2007; Gong et al., 2006) have verified that there is an optimal ratio between the spacing of the tools and the penetration of the rock and this also leads to an energy saving.
The pressure applied to each tool plays a key role on the penetration. All authors (Fuoco and Oreste, 2009; Grandori et al., 1995; Paul and Sikarski, 1965) agree that when the thrust reaches a certain value (critical pressure), which depends on the characteristics of the rock mass, the flake formation process begins and, beyond this value, an increase in pressure corresponds to a significant increase in penetration. Increasing the force on the tool, the size of the rock flakes increases, but the form of the flakes is less compressed and is therefore more suitable for possible reuse (Fig. 4) (Bruland, 1999).

Table 1 (Olbrecht and Studer, 1998) shows the percentages of flattened grains (where the height of the grain is negligible compared to the length and width) for different types of rock excavated with TBMs. The different types of rocks excavated by TBM are characterized by different shape indexes; among the rocks that have been studied, only excavated alluvial gravel is not flat and is therefore not suitable for concrete without a prior treatment.

The reuse of the material excavated by TBMs, assuming the mineralogical composition of the material is suitable and that the material is not contaminated by harmful substances, is critical because of the large quantity of fines and because of the geometry of the granules. In fact, granules larger than $8 \mathrm{~mm}$, are generally too flat and not cubic enough. Smaller grains than $8 \mathrm{~mm}$ generally have the necessary geometric requirements for use as aggregates for concrete; this has been demonstrated for the excavated material obtained for the AlpTransit project (AlpTransit Startseite, 2011; Thalmann, 1999) and a recent study on granitic material obtained from the excavation of the Aica exploratory tunnel of the Brenner Base Tunnel (Pepino, M., 2009). 
Am. J. Environ. Sci., 7 (4): 338-347, 2011

Table 1: Shape effects for different materials excavated using TBMs (Olbrecht and Studer, 1998)

\begin{tabular}{|c|c|c|c|}
\hline Designation & Source & Porosity \% vol & $\begin{array}{l}\text { Percentage of non- } \\
\text { cubical grains }(8 / 16)\end{array}$ \\
\hline Leventina gneiss biotite & Exploration tunnel polmengo & 36.6 & 74 \\
\hline muscovite gneiss & tunnel metre:387....390 & 42.1 & 76 \\
\hline Calcareouse sgale & Kandertal area & & \\
\hline Biotite gbelss grom & Exploration tunnel & 37.2 & 77 \\
\hline $\begin{array}{l}\text { Lucomagno zone shale- } \\
\text { like and slightly porphyritic }\end{array}$ & Polmengo tunnel metre: 4600 & & \\
\hline Calcareos shale & $\begin{array}{l}\text { Exploration tunnel frutigen } \\
\text { section } 100 \ldots 1500 \mathrm{~m}\end{array}$ & 42.3 & 65 \\
\hline Siliclois limestone & $\begin{array}{l}\text { Exploration tunnel frutigen } \\
\text { tunnel metre: } 6500\end{array}$ & 41.8 & 89 \\
\hline Alluvial gravel & Swiss midland & 26.0 & 24 \\
\hline
\end{tabular}

A larger spacing than $100 \mathrm{~mm}$ has been examined; some applications on granite have shown that this spacing leads to a good excavation efficiency and provides twice the amount of material with sizes larger than $32 \mathrm{~mm}$, compared to the normal spacing variables of between 70-90 mm (Thalmann, 1999).

Muck treatment for recovery optimisation: Muck treatment can be divided into: comminution, screening, classification. Different products are obtained with these processes: useful material, solid waste, sludge and wastewater. The latter has to undergo a further treatment before it leaves the treatment cycle.

Crushers are used to reduce the size of the debris. A classification of the primary comminution systems can be made and the following types of machines can be distinguished: Jaw crushers, rotary crushers, roller mills, impact crushers.

A crushing plant is usually located outside a tunnel and it can be powered by conveyor belts from the face or by dumper full of material. Alternatively, in order to facilitate transport of the muck, it can be convenient to design the system in a different way; for example, by providing an underground primary crushing plant, whenever there is sufficient space to accommodate the muck.

A frequently used parameter to indicate the change in size of the crushed material is the ratio $\rho$, which takes into account the size of a precise percentage of passing material at the entrance and exit of the crusher Eq. 2:

$\rho=\frac{D_{80}}{d_{80}}$

where, $\mathrm{D}_{80}$ is the diameter for which there is $80 \%$ of passing material, concerning the input material, while $\mathrm{d}_{80}$ refers to the same diameter at the exit.

The shape of the output product depends on the material and on the type of machine. The cubic index of particles is the ratio between the area of a cube of equal volume of the particle and the area of the real particle. Machines working at full load and with a low reduction ratio usually give a better cubicity than those working at high reduction ratios.

Furthermore, the percentage of fines increases in proportion to the reduction ratio, therefore subsequent comminution steps with different machines produce less fines than a single comminution step.

Table 2 summarizes the characteristics of different comminution machines and a mark is given for each behaviour characteristic and with reference to the adaptability to the characteristics of the muck produced in the tunnel.

The screening is conducted later on, after comminution of the rock, in order to obtain separate and different size classes, depending on the use of the rock at the end of the treatment. Particle size screens are used to select the materials. These can be divided into mobile screens, rotatory screens (Trommel) and vibrating screens. While the former are used for coarse screening before from the mills, vibrating and Trommel screens allow further size classifications inside the processing plants. Bar grids is the most common type of screen and are mainly used to prevent large pieces from entering the machine.

\section{DISCUSSION}

The Gotthard tunnel case study: The Lötschberg (34.6 km long) and Gotthard (57 km long) tunnels are part of the large AlpTransit project (AlpTransit Startseite, 2011); the first tunnel, which represents the first phase of the project, was opened in 2007, while the Gotthard base tunnel, which should be opened in 2017, will shorten the route between Altdorf, Uri Canton and Biasca in the Ticino Canton in Switzerland by $40 \mathrm{~km}$ and it will offer a quick link between Milan and Basel. 
Am. J. Environ. Sci., 7 (4): 338-347, 2011

Table 2: Communication machine behaviour vs. machine and rock characteristics (Legend: + low; ++ medium; +++ high; ++++ very high)

\begin{tabular}{|c|c|c|c|c|c|}
\hline \multirow[b]{2}{*}{ Comminution } & \multirow[b]{2}{*}{ Machine } & \multicolumn{4}{|c|}{ Behavior According to the rock behavior } \\
\hline & & Hardness & Abrasion & Moisture condition & adhesion \\
\hline & Single toggle-joint jaw crushers & +++ & +++ & + & \\
\hline & Double toggge-joint jaw crushers & +++ & ++ & + & \\
\hline \multirow[t]{5}{*}{ Primary } & Gyratory crushers & +++ & +++ & & \\
\hline & Roller mills & + & + & +++ & +++ \\
\hline & Impact crushers & ++ & ++ & ++ & ++ \\
\hline & Single toggle-joint jaw crushers & +++ & ++ & + & \\
\hline & Double toggle-joint jaw crushers & +++ & ++ & + & \\
\hline \multirow[t]{7}{*}{ Secondary } & Gyratory crushers & +++ & +++ & & \\
\hline & Roller mills & + & + & +++ & +++ \\
\hline & Impact crushers & ++ & ++ & ++ & ++ \\
\hline & Cone crushers & +++ & +++ & & \\
\hline & Toothed roll crushers & + & + & +++ & +++ \\
\hline & Impulse crushers & & ++ & ++ & ++ \\
\hline & & \multicolumn{4}{|c|}{ Behavior According to the rock machine characteristics } \\
\hline \multirow[t]{2}{*}{ Comminution } & Machine & Feed & Ratio & Product size & Shape index \\
\hline & Single toggle-joint jaw crushers & +++ & +++ & + & + \\
\hline \multirow[t]{6}{*}{ Primary } & Double toggle-joint jaw crushers & ++ & ++ & + & + \\
\hline & Gyratory crushers & +++ & ++ & + & ++ \\
\hline & Roller mills & + & + & +++ & ++ \\
\hline & Impact crushers & ++ & ++++ & ++ & +++ \\
\hline & Single toggle-joint jaw crushers & +++ & +++ & + & + \\
\hline & Double toggle-joint jaw crushers & ++ & ++ & + & + \\
\hline \multirow{6}{*}{ Secondary } & Gyratory crushers & ++++ & ++ & + & ++ \\
\hline & Roller mills & + & + & +++ & ++ \\
\hline & Impact crushers & ++ & ++++ & ++ & +++ \\
\hline & Cone crushers & ++++ & +++ & ++ & +++ \\
\hline & Toothed roll crushers & + & + & +++ & ++ \\
\hline & Impulse crushers & ++ & ++++ & ++ & +++ \\
\hline
\end{tabular}

The construction of two tunnels involves the production of large quantities of excavated material: 24 Mt (corresponding to $13.3 \mathrm{Mm}^{3}$ ) will be created from the Gotthard base tunnel. AlpTransit has three main objectives: to reuse most of the excavated material, to economically optimize the management of the material and to minimize the impact on the environment (Olbrecht and Studer, 1998).

Three operating principles were taken into account at the Gotthard Tunnel:

- The aggregates for the concrete should be obtained from their own sites

- The transport and intermediate storage must be of a low-emission type

- Noise and dust emissions should comply with the legal limits

The muck of better quality extracted from the Gotthard tunnel is used for the production of aggregates for concrete, after being suitably treated at the site. The excavated material that is not suitable for the production of aggregates for concrete and not used for the construction of the tunnel is removed and offered to third parties:
- The material from the Erstfeld and Amsteg work sites is transported by rail and by boat to the nearby estuary of the river Reuss, where it is deposited in the Lucerne Lake, in order to restore the natural conditions of the delta, which has been altered because of the extraction of gravel. The aim is to create six new islands through the use of $2 \mathrm{Mt}$ of material

- The waste gravel material in Sedrun, covers the demand of this products of the entire region, while the remaining amount is disposed off in the Bugnei and Claus valleys

- In Faido and in Bodio, part of the unused muck is transported, through a conveyor belt, to the nearby stone quarries of Cavienca and Buzza di Biasca, where it is used for the renaturation of these sites

About $46 \%$ of excavated material is reused in the project for the construction of embankments or for the production of aggregates for concrete, while about $53 \%$ is sold to third parties for environmental restoration and construction material and only $1 \%$ is sent to landfills. The most important muck treatment plant of the Gotthard tunnel is located in Bodio, where a total of 9.4 Mt of muck from the tunnel will be treated. 


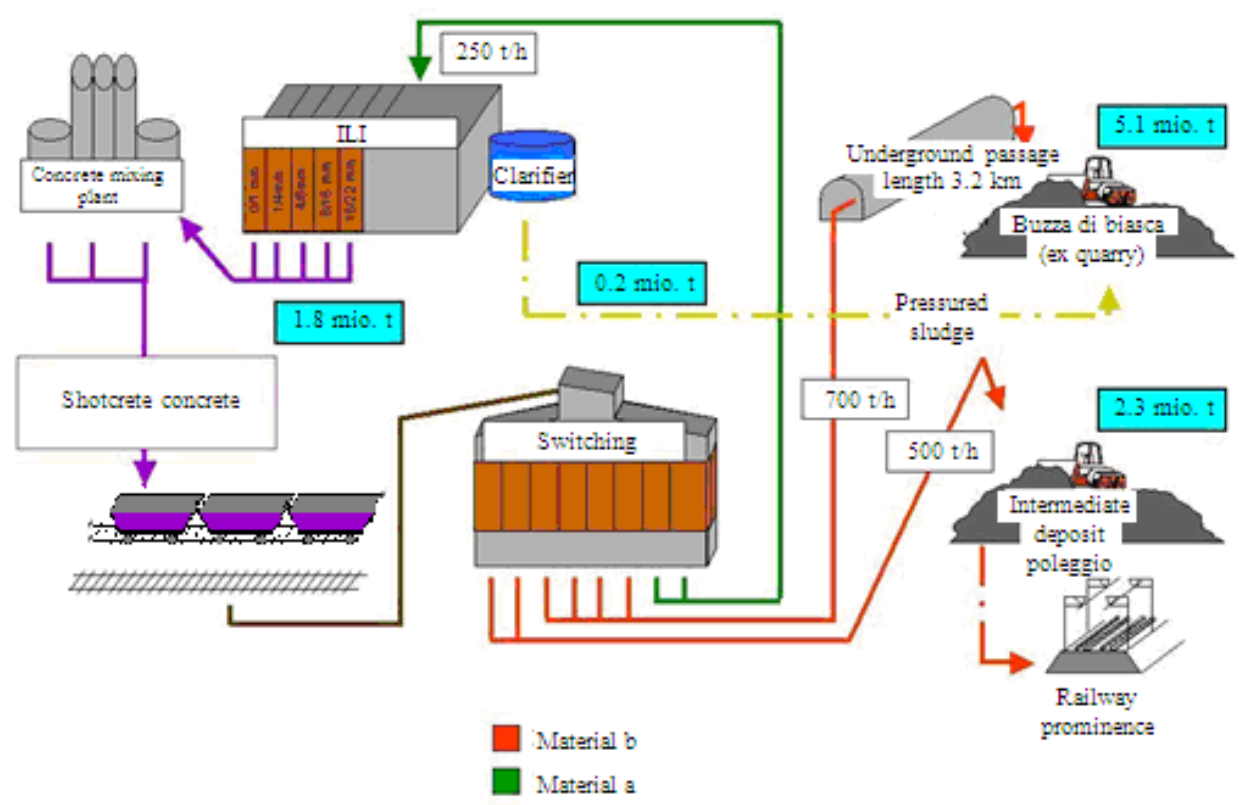

Fig. 5: Working process of the excavated material in Bodio (A) Material used for concrete, (B) Poor material used for embankments or landfilled) (AlpTransit Startseite, 2011)

The system at Bodio (Fig. 5) (AlpTransit Startseite, 2011) consists of three structures with different functions: the sorting plant, which separates and makes a first classification of the materials from the tunnel, the processing plant and the concreting plant.

The main uses of the material treated in Bodio concern the creation of new railway embankments (19\%), the environmental restoration (60\%) and the production of aggregates for concrete $(21 \%)$. The aggregates produced at the Bodio plant will be used for the construction of $31.5 \mathrm{~km}$ of tunnel.

The raw material is screened before it reaches the sorting plant and the larger components than $150 \mathrm{~mm}$ are sent to a shock crusher.

A series of screens inside the treatment plant separates the material: material $\mathrm{A}$, of $16 / 150 \mathrm{~mm}$, is sent to the ILI (Aggregate Processing Plant); material types B or $A$, of $0 / 16 \mathrm{~mm}$, are sent for intermediate storage and then used for the construction of embankments.

The aggregate treatment for the production of concrete (material type A) involves the use of an initial cleaning plant which removes finer particles. The obtained sludge, which can reach $12 \%$ of the total muck, should be deprived of water and then made to undergo an appropriate treatment.

The $16 / 150 \mathrm{~mm}$ raw material is sent for screening where it is divided into 50/150, 25/50 and $4 / 25 \mathrm{~mm}$ fractions. The $4 / 25 \mathrm{~mm}$ class is then sent to a vertical impact crusher who weigh 7.8 tons, has a power of 160 $\mathrm{kW}$ and an efficiency of $80-150 \mathrm{t} \mathrm{h}$. The $25 / 50 \mathrm{~mm}-$ $50 / 150 \mathrm{~mm}$ classes are sent to cone crushers which weigh 11.5 tons and have a power of $130 \mathrm{~kW}$ and an efficiency of 75-100 t/h. This material is then sent for a new screening process which allows to be divided into $4 / 11 \mathrm{~mm}$ and 11/24 $\mathrm{mm}$ and above $24 \mathrm{~mm}$ classes. Part of the coarser material (> $24 \mathrm{~mm}$ ) is put through the first screening, while the $4 / 11 \mathrm{~mm}-11 / 24 \mathrm{~mm}$ fractions are sent to friction drums, which round off the edges of the fragments and smooth the rough surfaces. A third set of sieves separates the treated material into the gravel needed for concrete production.

All the fines $(<4 \mathrm{~mm})$ are fed into a thickener, are passed through a hydrocyclone, to eliminate more water and then through some screens that separate the 1/4 $\mathrm{mm}$ component from the $0 / 1 \mathrm{~mm}$ one, which is carried first to a thickener, then to a hydrocyclone and finally to a filter.

All the sludge produced and present in the aqueous phase is first sent to a settling tank and then to a filter press that reduces the water content even more. The sludge from the filter press is sent to the Buzza di Biasca quarry.

The storage plant allows about 18,000 tons of aggregates to be stored. The level of material must be maintained above $70 \%$ of capacity, so that it can also be supplied at night and during weekends, when the ILI is 
not operating. The concreting plant removes the granulometric fractions that are necessary for the production of concrete and sends them along the tunnel to the Bodio and Faido sites.

Currently, the ILI plant of Bodio produces an excess of aggregates in the 1/ 4 and 4/ $8 \mathrm{~mm}$ classes, because the demand for sand, used for shotcrete in the tunnels, is greater than the amount that was forecast for the project. To solve this problem, the coarse fraction is either stored in temporary storage areas or put back into the cycle and re-crushed. This second solution, however, leads to some disadvantages, such as increased wear of the machines and higher sand production costs.

The Gotthard tunnel is mainly excavated in massive rocks which have a high content of mica with a smaller diameter than $2 \mathrm{~mm}$ and this leads to an increase in the percentage of fines during the treatment process. The limits of acceptability for the mica content imposed by AlpTransit have been assessed through microscopic analysis on the $0.25 / 0.5 \mathrm{~mm}$ fraction.

Moreover, because of the humidity and high temperatures in the Gotthard base tunnel, it should be considered that ASR could occur in concrete composed of recycled aggregates. This reaction develops more easily, in these conditions. The reactivity of the raw material is measured by means of a "microbar" test, according to the procedure described in AFNOR pages 18-558 (Leemann et al., 2005).

The studies have shown that the geological formation that could be responsible for this reaction is connected to some types of gneiss.

The problem of the elimination of the risk of damage because of alkali-aggregate reactions in concrete is not easy to resolve. It is clear that the elimination of the risk for concrete production could be achieved by using healthy aggregates, free of potentially reactive mineral forms.

Most reliable tests used to assess the potential reactivity of aggregates require rather long periods (at least three months).

A solution to the problem may be found in those measures that are used to help keep the laid concrete dry. The absence of water would lead to a "peaceful coexistence" of the reactive aggregates with the alkalis (Collepardi et al., 2002).

The tests carried out on the concrete made of recycled aggregates have shown that its quality is high. However, due to the higher percentage of voids (about $40 \%$ compared to the $25 \%$ of the aggregates with a rounded shape), the necessity of cement in the mixture is greater.

If the recovery process of the Gotthard tunnel muck is examined, it can be seen that this process could lead to great benefits, not only from the environmental point of view, but also concerning the economic contest. The costs of the tests that need to be carried out systematically on the excavated material and the construction costs of the facilities that would be used to treat the muck in an adequate way reach about 8 million Swiss francs. The savings, due to the lower costs for the purchase of sand and gravel from outside producers and the reduction in the transport of the materials out of the site, can be estimated as 100 million Swiss francs.

\section{CONCLUSION}

This study highlights the importance of the recovery of muck from the excavation of a tunnel, especially when a considerable amount of excavated material and aggregates is required.

The main problems connected to the recovery of muck have been described, thanks to the study conducted by researchers at the Politecnico di Torino, as part of the RE-MUCK research project: the immediate evaluation of the quality of muck at the excavation face in order to decide whether to recover it or whether it is better to place the material in a landfill; the analysis of the petrographic characteristics and the analysis of the dangerous alkali-aggregate reaction that may develop in concrete, which is the main cause of its rapid deterioration; the most suitable treatment techniques in installations outside the tunnel, especially when rock excavation is by TBM (which today is more and more frequent) and which leads to generally flattened fine grains; strategies for TBM excavation to obtain larger sized and slightly flattened grains, that is, with fine features that are suitable for reuse as aggregates for concrete; procedures to ensure the recovery of the excavated material in an environmentally friendly manner and convenient from an economic point of view.

Finally, a significant case-history has been shown that deals with the recovery of the muck from the Gotthard Base Tunnel, which is now the world's most advanced site concerning this type of activity. The characteristics of the separation plants situated at the main and auxiliary tunnel portals have been shown and the amount of material treated for reuse purposes has been discussed.

\section{REFERENCES}

AlpTransit Startseite, 2011 Der Einbau der Bahntechnik im Norden hat begonnen.

Blengini G.A. and E. Garbarino, 2010. Resources and waste management in Turin (Italy): The role of recycled aggregates in the sustainable supply mix. J. Cleaner Product., 18: 1021-1030. DOI: 10.1016/j.jclepro.2010.01.027 
Bruland A., 1999. Hard Rock Tunnel Boring. 1st Edn., ISBN: 8247102811, pp: 49.

Cardu, M., P. Oreste and T. Cicala, 2009. Analysis of the tunnel boring machine advancement on the bologna-florence railway link. Am. J. Eng. Applied Sci., $\quad 2$ : $416-420 . \quad$ DOI: 10.388844/ajeassp.2009.416.420

Collepardi, S., L. Coppola and R. Troli, 2002. Misure preventive per eliminare il rischio della reazione alcali-aggregato nei pavimenti industriali. Encon. J. Anno VII, 19: 38-40.

Fuoco, S. and P. Oreste, 2009. The tunnel boring machine advancements in horizontal and up-hill tunnels. Am. J. Applied Sci., 6: 1126-1132. DOI: 10.3844/ajassp.2009.1126.1132

Gertsh, R., L. Gertsh and J. Rostami, 2007. Disc cutting tests in colorado red granite: Implications for TBM performance prediction. Int. J. Roc. Mecha. Minin. Sci., 44: 238-246. DOI: 10.1016/j.ijrmms.2006.07.007

Girmscheid, G., 2008. Baubetrieb und Bauverfahren im Tunnelbau. Verlag Ernst and Sohn, Berlin, ISBN: 9783433018521, pp: 694.

Gong, Q.M., J. Zhao and A.M. Hefny, 2006. Numerical simulation of rock fragmentation process induced by two TBM cutters and cutter spacing optimization. Tunnell. Underground Space Technol., 21: 263-263. DOI: 10.1016/j.tust.2005.12.124
Gong, Q.M., J. Zhao and Y.S. Jiang, 2007. In situ TBM penetration tests and rock mass boreability analysis in hard rock tunnels. Tunnel. Underg. Spac. Technol., 22: 303-316. DOI: 10.1016/j.tust.2006.07.003

Grandori, R., M. Sem, A. Lembo Fazio and R. Ribacchi, 1995. Tunnelling By Double Shield TBM In the Hong Kong Granite. Proceedings of the 8th ISRM Congress, Sept. 25-29, Tokyo, Japan, 569-574.

Leemann, A., C. Thalmann and W. Studer, 2005. Alkali-aggregate reaction in Swiss tunnels. Mater. Struct., 38: 381-386. DOI: 10.1007/BF02479305

Olbrecht, H.P. and W. Studer, 1998. Use of TBM chip as concrete aggregate. Mater. Struct., 31: 184-187. DOI: $10.1007 / \mathrm{BF} 02480396$

Paul, B. and D.L. Sikarski, 1965. Rock Mechanics - A Preliminary Theory of Static Penetration by a Rigid Wedge into a Brittle Material. In: AIME Transactions.

Pepino, M., 2009. Scavo meccanizzato di gallerie: previsione della qualità del marino nell'ottica del suo riutilizzo. Tesi di laurea, Politecnico di Torino.

Thalmann, C., 1999. Concrete Aggregate Production with TBM-muck Experiences gained on the AlpTransit Tunnel Projects. B.I.G., pp: 11. 